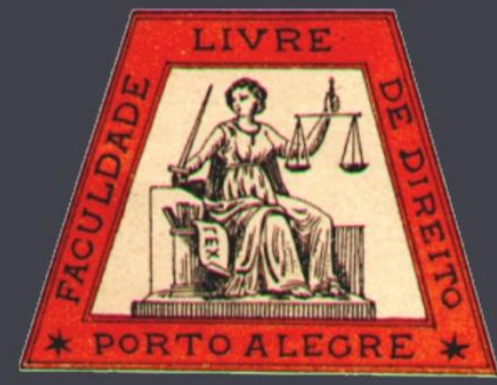

\title{
Teoria do Direito e da Constituição no contexto do neoconstitucionalismo pós-positivista: análise quanto à racionalidade
}

\section{Theory of Law and of the Constitution in the context of post-positivist neo-constitutionalism: analysis of rationality}

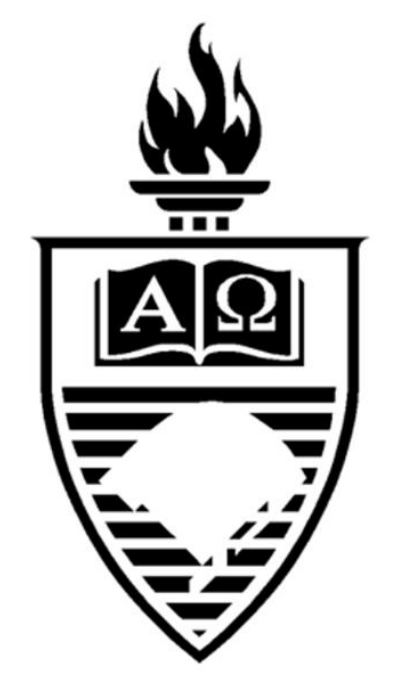

\section{Carla Panza Bretas}

Centro Universitário Autônomo do Brasil

Kennedy Josue Greeca de Mattos

Centro Universitário Autônomo do Brasil

Paulo Ricardo Schier

Centro Universitário Autônomo do Brasil

\section{UFRGS}




\title{
Teoria do Direito e da Constituição no contexto do neoconstitucionalismo pós-positivista: análise quanto à racionalidade
}

\author{
Legal and Constitutional Theory in the context of post-positivist neo-constitutionalism: analysis \\ regarding rationality
}

Carla Panza Bretas*

Kennedy Josue Greeca de Mattos ${ }^{* *}$

Paulo Ricardo Schier ${ }^{* * *}$

\begin{abstract}
REFERÊNCIA
BRETAS, Carla Panza; MATTOS, Kennedy Josue Greeca de; SCHIER, Paulo Ricardo. Teoria do Direito e da Constituição no contexto do neoconstitucionalismo pós-positivista: análise quanto à racionalidade. Revista da Faculdade de Direito da UFRGS, Porto Alegre, n. 35, vol. esp., p. 115-130, dez. 2016.
\end{abstract}

\begin{abstract}
RESUMO
O presente artigo busca reconstruir os passos históricos do constitucionalismo para entender o que é a sua nova fase que vem sendo denominada de neoconstitucionalismo. Para tanto, serão apresentadas as distinções conceituais entre constitucionalismo, neoconstitucionalismo, positivismo e pós-positivismo, bem como a mudança de paradigma quanto a teoria da norma. Por fim, será analisado se o atual estágio do constitucionalismo e da teoria da norma abriu espaço para o decisionismo no campo judicial.
\end{abstract}

\section{PALAVRAS-CHAVE}

Constitucionalimo. Teoria do Direito. Constituição. Neoconstitucionalismo. Pós-positivismo. Decisionismo. Ativismo judicial.

\section{ABSTRACT}

This article aims to reconstruct the historical steps of constitutionalism to understand what is its new phase that is being called neo-constitutionalism. For that, the conceptual distinctions between constitutionalism, neoconstitutionalism, positivism and post-positivism will be presented, as well as the paradigm shift regarding the theory of the norm. Finally, it will be analyzed whether the current stage of constitutionalism and normative theory has given room for decisionism in the judicial field.

\section{KEYWORDS}

Constitutionalism. Legal Theory. Constitution. Neoconstitutionalism. Post-positivism. Decisionism. Judicial Activism.

\section{SUMÁRIO}

Introdução. 1. A mudança de paradigma do direito constitucional. 1.1. Breve distinção entre constitucionalismo e neoconstitucionalismo, positivismo e pós-positivismo. 2. Teoria da norma no positivismo e no pós-positivismo. 2.1. O debate entre regras e princípios. 2.2. O modelo de princípios possibilita um défit de racionalidade e permite uma abertura para o decisionismo? Conclusão. Referências.

\section{INTRODUÇÃO}

\footnotetext{
* Mestranda em Direitos Fundamentais e Democracia pela UNIBRASIL. Analista judiciária no Tribunal Regional Eleitoral do Paraná.

** Graduação em Direito pela Pontifícia Universidade Católica do Paraná (1986). Juiz de Direito no estado do Paraná. Mestrando em Direitos Fundamentais e Democracia pela UNIBRASIL.

*** Doutor e Mestre em Direito Constitucional pela Universidade Federal do Paraná. Realizou estágio pós-doutoral na Universidade de Coimbra (Centro de Democracia e Direito Humanos do IGC, Ius Gentium Conimbrigae). Professor e Pesquisador do Programa de Mestrado em Direitos Fundamentais e Democracia do Centro Universitário UniBrasil.
} 
Estudar de que modo a Constituição irradia-se sobre o ordenamento jurídico é uma tarefa que deve ser constantemente exercitada pelos operadores do Direito. O direito não é algo estático e, por isso, torna-se essencial compreender como os reflexos decorrentes das mudanças sociais e filosóficas surgidas através dos tempos influenciam a interpretação da norma jurídica e, em especial, a função da Constituição. Esse é o desafio que se propõe no presente artigo.

\section{A MUDANÇA DE PARADIGMA DO DIREITO CONSTITUCIONAL}

\subsection{Breve distinção entre constitucionalismo e neoconstitucionalismo, positivismo e pós- positivismo}

A evolução histórica do constitucionalismo começou na idade antiga ${ }^{1}$, mas os primeiros marcos históricos expressivos somente foram observados no século XIII com a Magna Carta do Rei João Sem Terra (1215) e a Bula de Ouro dos

\footnotetext{
1 Sahid Maluf destaca como exemplos de sistema constitucional calcado em leis básicas: as leis de Creta, elaboradas por Minos; as leis de Licurgo e Solon; o regime jurídico de Atenas (Maluf, Sahid. Teoria geral do Estado. $23^{a}$ ed. rev. e atual. - São Paulo: Saraiva: 1995, p. 191).

${ }^{2}$ Maluf, Sahid. Teoria geral do Estado. $-23^{\mathrm{a}}$ ed. rev. e atual. - São Paulo: Saraiva: 1995, p. 191.

${ }^{3}$ Canotilho, J.J., Gomes. Direito Constitucional. $6^{\mathrm{a}}$ ed. Coimbra: Livraria Almedina, p. 61.

${ }^{4}$ Segundo J.J. Gomes Canotilho, o "conceito ideal de Constituição" identifica-se com os postulados políticosliberais e caracteriza-se por compreender que: "(a) a constituição deve consagrar um sistema de garantia da liberdade (esta essencialmente concebida no sentido do reconhecimento de direitos individuais e da participação dos cidadãos nos actos do poder legislativo através dos parlamentos); (b) a constituição contém o princípio da decisão de poderes, no sentido de garantia orgânica contra os abusos dos poderes estatais; (c) a constituição deve ser escrita (documento escrito)" (Canotilho, J.J., Gomes. Direito Constitucional. $6^{\mathrm{a}}$ ed. Coimbra: Livraria Almedina, p. 62-63).

${ }^{5}$ Maluf, Sahid. Teoria geral do Estado. $-23^{\mathrm{a}}$ ed. rev. e atual. - São Paulo: Saraiva: 1995, p. 192.

${ }^{6}$ Jorge Miranda adverte que o Direito constitucional norteamericano não começou com a Constituição de 1787, mas sim com os diversos textos da época colonial que
}

húngaros $(1222)^{2}$, documentos que inauguraram a chamada "pré-história" do constitucionalismo ${ }^{3}$.

É evidente, porém, que àquelas Cartas não tinham a mesma significação que atualmente conferimos às Constituições ${ }^{4}$, pois não chegavam a limitar efetivamente o absolutismo dos reis divinizados, mas ainda assim serviam como "tentativas de pacificação entre o príncipe e o povo" 5 .

Somente com o desenvolvimento das ideias liberais e o surgimento das primeiras Constituições escritas - Estados Unidos da América (1787) ${ }^{6}$ e França (1791) - é que inaugura-se o denominado Constitucionalismo moderno $^{7}$ ou formal ${ }^{8}$.

No campo filosófico desse mesmo contexto histórico, a passagem do Estado absolutista para o Estado liberal fez com que a lei fosse vista como a expressão superior da razão. $\mathrm{O}$ Direito foi arrebatado pela onda positivista ${ }^{9} \mathrm{e}$ passou a compreender o sistema jurídico como algo completo, autossuficiente e que eventuais lacunas seriam resolvidas dentro do próprio

integravam os princípios, valores e símbolos da Declaração de Independência, Declaração da Virgínia e outras Declarações de Direitos que antecederam o texto constitucional (Miranda, Jorge. Teoria do Estado e da Constituição. Coimbra: Coimbra Editora, 2002, p. 125-126. ${ }^{7}$ Maluf, Sahid. Teoria geral do Estado. $-23^{\mathrm{a}}$ ed. rev. e atual. - São Paulo: Saraiva: 1995, p. 192.

${ }^{8}$ Moraes, Alexandre de. Direito constitucional. $-28^{\mathrm{a}}$ ed. São Paulo: Atlas, 2012, p. 1.

9 “O positivismo jurídico foi a importação do positivismo filosófico para o mundo do Direito, na pretensão de criar-se uma ciência jurídica, com características análogas às ciências exatas e naturais. A busca de objetividade científica, com ênfase na realidade observável e não na especulação filosófica, apartou o Direito da moral e dos valores transcendentes. Direito é norma, ato emanado do Estado com caráter imperativo e força normativa. A ciência do Direito, como todas as demais, deve fundar-se em juízos de fato, que visam ao conhecimento da realidade, e não em juízos de valor, que representam uma tomada de posição diante da realidade. Não é no âmbito do Direito que se deve travar a discussão acerca de questões como legitimidade e justiça" em Barroso, Luís Roberto. Interpretação $e$ aplicação da constituição: fundamentos de uma dogmática constitucional transformadora. $6^{\mathrm{a}}$ ed. rev., atual. e ampl. São Paulo: Saraiva, 2004, p. 323. 
direito (costumes, analogia e, excepcionalmente, princípios gerais do direito), sem qualquer tarefa criativa por parte do intérprete.

$\mathrm{Na}$ aplicação desse direito "puro e idealizado" 10 , o Juiz não detinha margem para avaliar a justiça da lei. Cumpria-lhes, apenas, realizar o papel de árbitro imparcial e realizar o processo de interpretação mediante a subsunção do fato à norma. Ao juiz cabe, apenas, dizer as palavras frias da lei ${ }^{11}$.

Compreendem-se tais pensamentos quando recordamos que os mesmos foram impulsionados pelas ideias de Jean JacquesRoussea $^{12}$, esculpidas dentro do encaminhamento das ideias da Revolução Francesa e deflagradas como uma grande reação da burguesia contra as prerrogativas e privilégios da nobreza e do clero.

$\mathrm{O}$ apogeu do positivismo jurídico foi alcançado com a obra-prima clássica "Teoria pura do direito" de Hans Kelsen ${ }^{13}$ que, em apartadas linhas, resume dita teoria filosófica pela i) aproximação quase plena entre o direito e a moral; ii) unidade do ordenamento jurídico e emanação do Estado; iii) completude do ordenamento jurídico, que contém conceitos e instrumentos suficientes e adequados para solução de qualquer

\footnotetext{
${ }^{10}$ Barroso, Luís Roberto. Interpretação e aplicação da constituição: fundamentos de uma dogmática constitucional transformadora. $6^{\mathrm{a}}$ ed. rev., atual. e ampl. São Paulo: Saraiva, 2004, p. 312-313.

${ }^{11}$ Montesquieu. Do espírito das leis. São Paulo: Martin Claret, 2010, p. 172.

12 “A primeira e mais importante consequência dos princípios acima estabelecidos está em que somente a vontade geral tem possibilidade de dirigir as forças do Estado, segundo o fim de sua instituição, isto é, o bem comum" (Rousseau, J. -J.. Do contrato social. Disponível em

http://www.dominiopublico.gov.br/download/texto/cv0001 4a.pdf, acesso em 04 de outubro de 2015.

${ }^{13}$ Kelsen. Hans. Teoria pura do direito. $4^{\mathrm{a}}$ ed. Coimbra, 1976.

${ }^{14}$ Barroso, Luís Roberto. Interpretação e aplicação da constituição: fundamentos de uma dogmática constitucional transformadora. $6^{\mathrm{a}}$ ed. rev., atual. e ampl. São Paulo: Saraiva, 2004, p. 323.

${ }^{15}$ Barroso, Luís Roberto. Interpretação e aplicação da constituição: fundamentos de uma dogmática
}

caso, inexistindo lacunas; iv) a validade da norma depende apenas da adequação do seu procedimento, independentemente do seu conteúdo; v) para a aplicação da norma cabe ao interprete apenas realizar a tarefa de subsunção ${ }^{14}$.

No entanto, como bem insinuou Luis Roberto Barroso, naquele fetiche da lei e do legalismo acrítico, "Têmis, vedada, balança na mão, é o símbolo maior, musa de muitas gerações: o Direito produz ordem e justiça, com equilíbrio e igualdade. Ou talvez não seja bem assim"15.

De fato, o positivismo jurídico serviu de justificação para os horrores praticados pelos nazifascistas durante a Segunda Guerra Mundial e não resistiu quando a vitória dos Aliados fez cair o véu que os encobria ${ }^{16}$. Abriu-se o caminho para a reaproximação do direito e a ética ${ }^{17}$.

Assim, o pós-positivismo surgiu como uma nova dogmática constitucional que, segundo Luis Roberto Barroso, traduz-se na "designação provisória e genérica de um ideário difuso, no qual se incluem a definição das relações entre valores, princípios e regras, aspectos da chamada nova hermenêtica e a teoria dos direitos

constitucional transformadora. $6^{\mathrm{a}}$ ed. rev., atual. e ampl. São Paulo: Saraiva, 2004, p. 313.

16 "Esses movimentos políticos e militares ascenderam ao poder dentro do quadro de legalidade vigente e promoveram a barbárie em nome da lei. Os principais acusados de Nuremberg invocaram o cumprimento da lei e a obediência a ordens emanadas da autoridade competente. Ao fim da Segunda Guerra Mundial, a ideia de um ordenamento jurídico indiferente a valores éticos e da lei como uma estrutura meramente formal, uma embalagem para qualquer produto, já não tinha aceitação no pensamento esclarecido". Barroso, Luís Roberto. Interpretação e aplicação da constituição: fundamentos de uma dogmática constitucional transformadora. $6^{\mathrm{a}}$ ed. rev., atual. e ampl. São Paulo: Saraiva, 2004, p.325.

${ }^{17}$ Barroso, Luís Roberto. Interpretação e aplicação da constituição: fundamentos de uma dogmática constitucional transformadora. $6^{\mathrm{a}}$ ed. rev., atual. e ampl. São Paulo: Saraiva, 2004, p. 324/325. Em sentido oposto: Pozzolo, Suzanna. Un constitucionalismo ambíguo. In: Carbonel, Miguel. Neoconstitucionalismo(s). Madrid: Trotta, 2003, p. 187-210. 
fundamentais" ${ }^{18}$. As condições de validade das leis foram alteradas. Passou-se a exigir não só o atendimento dos aspectos formais de produção da lei, mas também a coerência de seu conteúdo frente os princípios constitucionais ${ }^{19}$, que "passam a ser a síntese dos valores abrigados no ordenamento jurídico" 20 .

É dentro desse ambiente filosófico que floresce o "novo direito constitucional" ou neoconstitucionalismo ${ }^{21}$, cujos frutos irradiaram por todo o ordenamento jurídico os valores abrigados nos princípios e regras constitucionais $^{22}$.

Porém é importante consignar que esse novo momento ${ }^{23}$ do direito constitucional não

${ }^{18}$ Barroso, Luís Roberto. Interpretação e aplicação da constituição: fundamentos de uma dogmática constitucional transformadora. $6^{a}$ ed. rev., atual. e ampl. São Paulo: Saraiva, 2004, p. 325.

${ }^{19}$ Ferrajoli, Luigi. Pasado y futuro des estado de derecho. In: Carbonell, Miguel. Neoconstitucionalismo(s). Madri: Editorial Trotta, 2003, p. 7.

20 Barroso, Luís Roberto. Interpretação e aplicação da constituição: fundamentos de uma dogmática constitucional transformadora. $6^{\text {a }}$ ed. rev., atual. e ampl. São Paulo: Saraiva, 2004, p. 325.

${ }^{21} \mathrm{O}$ conceito de neoconstitucionalismo não é uníssono, por isso, o título da obra de Miguel Carbonell "Neoconstitucionalismo(s)". (Madrid: Trotta, 2006) é muito respeitado pela doutrina Constitucional. Nesse sentido: Ávila, Humberto. "Neoconstitucionalismo": entre a "Ciência do Direito" e o "Direito da Ciência". In: Neto, Claudio Pereira de Souza; Sarmento, Daniel; Binenbojm, Gustavo (Coords.). Vinte Anos da Constituição Federal de 1988. Rio de Janeiro: Lumen Juris, 2009, p. 187-202.

22 Barroso, Luis Roberto. Neoconstitucionalismo $e$ constitucionalização do direito. Disponível em http://www.luisrobertobarroso.com.br/wpcontent/themes/L $\mathrm{RB} / \mathrm{pdf} /$ neoconstitucionalismo

_e_constitucionalizacao_do_direito_pt.pdf. Acesso em 04 de outubro de 2015. Na mesma linha de ideias, mas com uma visão um pouco mais ampla, Schier, Paulo Ricardo. A constitucionalização do direito no contexto da constituição de 1988. In: Clève, Clémerson Merlin (org). Direito constitucional brasileiro - teoria da constituição e direitos fundamentais. São Paulo: Revista dos Tribunais, Volume 1, 2014. "Assim, neste quadro, vê-se os seguintes fenômenos: (i) maior presença da constituição em detrimento da lei; (ii) maior presença do juiz em detrimento do legislador; (iii) maior participação dos princípios em importou na superação do constitucionalismo anterior. $\mathrm{Na}$ verdade, o "Constitucionalismo Contemporâneo conduz simplesmente a um processo de continuidade que agrega as novas conquistas que passa a integrar a estrutura do Estado Constitucional no período posterior à $2^{\mathrm{a}}$ Guerra Mundial" 24.

Segundo Luis Pietro Sanchís ${ }^{25}$, esse novo constitucionalismo, entendido na concepção de um modelo de Estado Constitucional de Direito ${ }^{26}$, decorre da convergência das tradições constitucionais europeia e norteamericana, o melhor desses dois mundos. Ou seja, forte

detrimento das regras; (iv) mais ponderação e menos subsunção; (v) vinculação do Estado à Constituição como "limitação", mas também como "prestação" e legitimação material; (vi) maior heterogeneidade axiológica dos textos constitucionais e, logo, mais pluralismo; (vii) aproximação entre direito e moral; (viii) ênfase na substância, sem contudo abandono da forma, do procedimento e, finalmente, (ix) eixo teórico fundado na teoria da argumentação sob perspectiva do pós-positivismo".

${ }^{23}$ Schier, Paulo Ricardo. A constitucionalização do direito no contexto da constituição de 1988. In: Clève, Clémerson Merlin (org). Direito constitucional brasileiro - teoria da constituição e direitos fundamentais. São Paulo: Revista dos Tribunais, Volume 1, 2014, p. 45-60.

${ }^{24}$ Streck, Lenio Luiz. Jurisdição constitucional e decisão jurídica $-4^{\mathrm{a}}$ ed. - São Paulo: Editora Revista dos Tribunais, 2014, p. 299

${ }^{25}$ Sanchis defende que a noção de neoconstitucionalismo pode ser observada sobre três distintos significados: i) tipo de Estado de Direito (forma de organização política); ii) Teoria do Direito (apta a explicar as características do dito modelo); iii) Ideologia (que justifica ou define a fórmula jurídica assim designada) - (Sanchis, Luís Prieto. Justicia constitucional y derechos fundamentales. Madrid: Trotta, 2003).

${ }^{26}$ A noção de Estado de Direito pode ser resumida com as palavras de Danilo Zolo: "entendido como um Estado moderno no qual o ordenamento jurídico - não a outros subsistemas funcionais - é atribuída a tarefa de 'garantir' os direitos individuais, refreando a natural tendência do poder político e expandir-se e a operar de maneira arbitrária", em Zolo, Danilo. Teoria e crítica do estado de direito. In: Costa, Pietro; Zolo, Danilo (orgs.) O estado de direito historia, teoria e crítica. São Paulo: Martins Fontes, 2006, p. 11 . 
conteúdo normativo (Europa) ${ }^{27}$ e garantia jurisdicional (EUA) ${ }^{28}$. No entanto, o autor pontua que para o neoconstitucionalismo, a Constituição deve ser transformadora de modo a condicionar a decisão da maioria - enquanto no constitucionalismo tradicional os direitos fundamentais eram pressupostos da democracia, no neoconstitucionalismo os direitos fundamentais são limites à democracia ${ }^{29}$.

Daí surge o protagonismo do papel do judiciário, em substituição ao protagonismo do legislativo como ocorrida no constitucionalisfmo tradicional, fruto do positivismo ${ }^{30}$. No entanto,

\begin{abstract}
${ }^{27}$ A tradição europeia é caracterizada por Sanchis como: i) programa de direito - A constituição estabelece o projeto político bem articulado, condiciona as futuras decisões coletivas, o propósito do modelo econômico e das ações estatais na esfera educacional, saúde, relações de trabalho e etc. ; ii) Texto jurídico supremo; iv) Vontade Geral - a constituição passa a encarnar a idéia roussoniana de "vontade geral". Mas a idéia de poder constituinte não se encerra em um texto único, mas é encarnada pelo legislativo, que teria um poder ilimitado (Sanchis, Luís Prieto. Neoconstitucionalismo y ponderación judicial. In: Carbonell, Miguel. Neoconstitucionalismo(s). Madrid: Editorial Trotta, 2003).
\end{abstract}

${ }^{28}$ São essas as caracterísitica atribuída por Sanchis à tradição norteamericana: i) supremacia da Constituição; ii) "pacto dos mínimos" - autonomia dos indivíduos como sujeitos privados e como agentes públicos; iii) garantia jurisdicional - o judiciário é considerado o mais neutro dos poderes, por se manter a margem do debate político; iv) limitação do poder político - através do poder constituinte do povo, em especial quanto ao Poder Legislativo; v) judicialismo (Sanchis, Luís Prieto. Neoconstitucionalismo y ponderación judicial. In: Carbonell, Miguel. Neoconstitucionalismo(s). Madrid: Editorial Trotta, 2003). 29 No mesmo sentido: Novais, Jorge Reis. Direitos fundamentais e justiça constitucional. Coimbra: Coimbra, 2012; Barroso, Luís Roberto. Curso de direito constitucional contemporâneo: os conceitos fundamentais e a construção do novo modelo - São Paulo: Saraiva, 2009, p. 69: "em um Estado democrático de direito, não subsiste a dualidade cunhada pelo liberalismo, contrapondo Estado e sociedade. O Estado é formado pela sociedade e deve perseguir os valores que ela aponta. Já não há uma linha divisória romântica e irreal separando culpas e virtudes".

${ }^{30}$ Ferrajoli, Luigi. "Pasado y futuro Del Estado de derecho". In: CARBONELL, Miguel (org.). como adverte Sanchís, isso não significou a supremacia dos tribunais sobre o legislativo, mas sim o equilíbrio entre eles ${ }^{31}$.

É nesse contexto que cresce a importância do Poder Judiciário, que passa a ser convocado para resolver questões polêmicas que envolvem a aplicação de princípios constitucionais colidentes. A antiga técnica da subsunção já não é mais suficiente para, por si só, apresentar respostas a essas novas questões (hard cases). Supera-se o pensamento de Montesquieu ${ }^{32}$ e exige-se o esforço no desenvolvimento de uma nova dogmática jurídica ${ }^{33}$.

Neoconstitucionalismo(s). Madrid: Trotta, 2003, p. 14-17. No mesmo sentido: Zagrebelsky, Gustavo. El derecho dúctil: ley, derechos, justicia. 6. ed. Madrid: Trotta, 2007, p. 21-4.

${ }^{31}$ Sanchis em crítica a Elias Dias (Sanchis, Luís Prieto. Neoconstitucionalismo y ponderación judicial. In: Carbonell, Miguel. Neoconstitucionalismo(s). Madrid: Editorial Trotta, 2003). Com uma visão particular quanto ao Direito Brasileiro, Humberto Ávila defende que não é correto asseverar que o Poder Judiciário deve ponderar sobre o Poder Legislativo (ou Executivo). Numa sociedade complexa e plural, é o Poder Legislativo o Poder onde, por meio do debate, se pode respeitar e levar em consideração a pluralidade de concepções de mundo e de valores, e o modo de sua realização (...) Num ordenamento constitucional que privilegia a participação democrática e reserva ao Poder Legislativo a competência para regular, por lei, um sem número de matérias, não se afigura adequado sustentar se passou do Poder Legislativo para o Poder Judiciário, nem que se deve passar ou é necessariamente bom que se passe de um para o outro" (Avila, Humberto. Neoconstitucionalismo: entre a ciência do direito e o direito da ciência. In: Sarmento, Daniel (Coord.) Filosofia e teoria constitucional contemporânea. Rio de Janeiro: Editora Lumen Juris, 2009, p. 202).

32 "os juízes da nação não são ... mais que a boca que pronuncia as palavras da lei, seres inanimados que desta lei não podem moderar nem a força nem o rigor" (Montesquieu. Do espírito das leis. São Paulo: Martin Claret, 2010, p. 172).

${ }^{33}$ Segundo Margarida Lacombe Camargo em seu texto $A$ nova hermenêutica. in: Sarmento, Daniel (Coord.) Filosofia e teoria constitucional contemporânea. Rio de Janeiro: Editora Lumen Juris, 2009, p. 337: “A Nova Hermeneutica surge num contexto de crítica à preponderância do método lógico silogísitico como fator de legitimação do Direito, conforme propugnado pelo silogismo jurídico". 


\section{TEORIA DA NORMA NO POSITIVISMO E NO PÓS-POSITIVISMO}

\subsection{O debate entre regras e princípios}

$\mathrm{Na}$ trajetória que levou ao esgotamento do pensamento positivista, os princípios foram conduzidos ao centro do sistema jurídico, superando-se a crença anterior de que os mesmos possuíam tão somente uma dimensão axiológica ${ }^{34}$.

Nesse contexto do pós-guerra, as Constituições dos Estados passaram a incorporar um grande número de princípios e direitos fundamentais, impondo aos seus Estados tanto o dever de não intervenção na esfera privada, como o desenvolvimento de políticas públicas em prol da efetivação de ditos direitos ${ }^{35}$. Como afirmou Daniel Sarmento, "nesse quadro, a Constituição foi deixando se ser vista como mero repositório de conselhos para os poderes políticos e se convertendo em norma jurídica"36.

Assim, a nova dogmática jurídica passou a difundir o entendimento de que as normas em geral, em especial as normas constitucionais, enquadram-se em duas espécies diversas: princípios e regras, cuja distinção conceitual estruturou a base da teoria normativo-material dos direitos fundamentais e um ponto de partida para

\footnotetext{
${ }^{34}$ Barroso, Luís Roberto. Interpretação e aplicação da constituição: fundamentos de uma dogmática constitucional transformadora. $6^{\mathrm{a}}$ ed. rev., atual. e ampl. São Paulo: Saraiva, 2004, p. 327.

${ }^{35}$ Pozzolo, Susanna. Un constitucionalismo ambiguo. In: Carbonell, Miguel. Neoconstitucionalismo(s). Madrid: Editorial Trotta, 2003.

${ }^{36}$ Sarmento, Daniel. Umbiquidade constitucional: os dois lados da moeda. Revista de Direito do Estado 2, 2006.

${ }^{37}$ Virgílio Afonso da Silva alerta que é comum no Brasil que a teoria dos princípios de Robert Alexy e a teoria estruturante de Friedrich Muller sejam defendidas como se fossem compatíeis entre si. No entanto, o autor esclarece que ambas as teorias fundam-se em premissas bastante diversas, pois "Muller defende que a definição do âmbito de
}

a resposta quanto aos possibilidades e limites da racionalidade no âmbito do direito ${ }^{37}$.

Ronald Dworkin capitaneia a doutrina preocupada com a nova dogmática e estabelece que tanto as regras quanto os princípios "apontam para decisões particulares acerca da obrigação jurídica em circunstâncias específicas, mas distinguem-se quanto à natureza da orientação que oferecem" 38 . Assim, sustenta que as regras, se válidas, são aplicadas ao modo tudo ou nada (all or nothing), ou seja, sendo válida a regra, a resposta por ela oferecida deve ser aceita. De outro viés, sendo inválida, a regra não poderá ser aproveitada para o resultado da decisão.

Quanto aos princípios, Dworkin esclarece que as consequências jurídicas decorrentes do preenchimento das condições estabelecidas pelos princípios não são verificadas automaticamente ${ }^{39}$. Aliás, nem mesmo as condições que tornam a aplicação dos princípios como necessárias podem ser estabelecidas de forma prévia. Ao contrário, os princípios apenas anunciam "uma razão que conduz o argumento em uma certa direção", mas (ainda assim) necessitam de uma decisão particular ${ }^{40}$. Os princípios não determinam a decisão, mas somente os seus fundamentos, que devem ser conjugados com outros fundamentos provenientes de princípios.

Daí a afirmação de que os princípios, ao contrario das regras, possuem uma dimensão de peso (ou importância), demonstrável na hipótese

proteção de cada direito fundamental é feito de antemão, por intermédio dos procedimentos e métodos de sua teoria estruturante e, principalmente, sem a necessidade de sopesamente; enquanto Alexy defende que não há decisões correteas no âmbito dos direitos fundamentais que não sejam produto de um sopesamento" (Da Silva, Virgílio Afonso. Interpretação Constitucional e sincretismo metodológico. In: Da Silva, Virgílio Afonso (org.). Interpretação constitucional $1^{\mathrm{a}}$ ed. - São Paulo: Melheiros, 2005, p. 137.

${ }^{38}$ Dworkin, Ronald. Levando os direitos a sério. - São Paulo: Martins Fontes, 2002, p. 39.

${ }^{39}$ Dworkin, Ronald. Levando os direitos a sério. - São Paulo: Martins Fontes, 2002, p. 40.

${ }^{40}$ Dworkin, Ronald. Levando os direitos a sério. - São Paulo: Martins Fontes, 2002, p. 41. 
de colisão. Ou seja, quando dois ou mais princípios intercruzam-se torna-se imperioso avaliar quais deles é mais importante para o caso, mas sem que isso implique na perda da validade daquele princípio que deve ceder. De outro lado, as regras não comportam essa mesma dimensão. Verificado o conflito entre regras, a decisão deverá verificar qual delas é válida e qual delas deve ser abandonada ou reformulada ${ }^{41}$.

No entanto, embora as concepções de Ronald Dworkin tenham sido fortemente aceitas por outros autores, ainda assim pode-se identificar alguns pontos de divergências. Robert Alexy, por exemplo, aproveitou grande parte das considerações quanto a diferenciação entre regras e princípios ${ }^{42}$, mas criticou Dworkin por considera-lo muito simples ${ }^{43}$. Esse é o ônus de todo aquele que ousa ser o primeiro.

Robert Alexy também diverge de Dworkin por entender que não existe apenas uma diferença gradual entre regras e princípios, mas uma diferença qualitativa. Explica-se. Segundo Alexy, os princípios exigem que algo seja realizado na maior medida possível dentro das possibilidades jurídicas e fáticas existentes. Eles não contém um mandamento definitivo, mas somente prima facie (mandamentos de otimização ${ }^{44}$ ). Já as regras exigem que seja feito exatamente aquilo que elas ordenam. Elas têm uma determinação da extensão do seu conteúdo em face das circunstâncias fáticas e jurídicas. Se essa determinação não

\footnotetext{
${ }^{41}$ Dworkin, Ronald. Levando os direitos a sério. - São Paulo: Mar002, p. 42 e 43.

${ }^{42}$ Alexy e Dworkin diverge, por exemplo, quanto ao tipo de direitos englobados pelos princípios. Segundo Alexy, os princípios podem se referir tanto a direitos individuais quanto a direitos coletivos. A relação dos princípios com direitos coletivos exige a criação ou manutenção de situações que satisfaçam, na maior medida possível diante das possibilidades jurídicas e fáticas, critérios que vão além da validade e satisfação do direito. Sob outro ponto de vista, Dworkin defende que só existem princípios relacionados com direitos individuais. Normas que se referem à direitos coletivos podem ser consideradas como 'políticas'. Robert, Alexy. Teoria dos direitos fundamentais. - São Paulo: Malheiros Editores, 2008, p. 114/116.
}

falhar diante das possibilidades jurídicas e fáticas, então as regras assumem um caráter definitivo ${ }^{45}$.

Dito autor estabelece, ainda, que a diferenciação entre regras e princípios também pode ser observada no caso de conflito entre elas. Em poucas linhas pode-se dizer que segundo Alexy, no caso de conflito entre regras a solução somente será alcançada caso se introduza em uma das regras uma clausula de exceção que elimine o conflito, ou se uma das regras for declarada inválida. Já em se tratando de colisão entre princípios, o autor entende que um dos princípios em jogo deve ceder, mas sem que isso implique na declaração de invalidade do outro, tão pouco introduzida uma clausula de exceção. Segundo defende, "o que ocorre é que um dos princípios tem precedência em face do outro sob determinadas condições. Sob outras condições a questão da precedência pode ser resolvida de forma oposta" 46 . Isso é o que o autor chama de "lei da colisão".

Em resumo, segundo Robert Alexy, o conflito entre regras ocorre na dimensão da validade, enquanto a colisão entre princípios ocorrem na dimensão de peso ${ }^{47}$.

No caso de colisão entre princípios, Robert Alexy demonstra existir uma relação de tensão que não se resolve de imediato com a determinação de prevalência de um sobre o outro, mas sim em função da ponderação ${ }^{48}$ entre os princípios colidentes, quando um deles, de acordo

\footnotetext{
${ }^{43}$ Robert, Alexy. Teoria dos direitos fundamentais. - São Paulo: Malheiros Editores, 2008, p. 104.

${ }^{44}$ No mesmo sentido: Silva, Virgílio Afonso da. "Direitos fundamentais: conteúdo essencial, restrições e eficácia." (2009). Em sentido oposto segue a teoria estruturante do direito de Friedrich Muller (Muller, Friedrich. Tesis acerca de la estrutura de las normas jurídicas. Madrid: CEPC, 1989).

${ }^{45}$ Robert, Alexy. Teoria dos direitos fundamentais. - São Paulo: Malheiros Editores, 2008, p. 90 e 91.

${ }^{46}$ Robert, Alexy. Teoria dos direitos fundamentais. - São Paulo: Malheiros Editores, 2008, p. 92 e 93.

${ }^{47}$ Robert, Alexy. Teoria dos direitos fundamentais. - São Paulo: Malheiros Editores, 2008, p. 94

${ }^{48} \mathrm{O}$ conceito de ponderação para os efeitos aqui estudados pode ser resumido como " a técnica jurídica de solução de
} 
com o caso concreto, recebe a prevalência sobre o outro e cria uma verdadeira regra ${ }^{49}$. Os princípios possuiriam apenas uma dimensão de peso e não determinariam as consequências normativas de forma direta, ao contrário das regras. Isso faz com que os princípios também sejam aplicados segundo o modo tudo ou nada.

Não obstante essas discordâncias teóricas entre Ronald Dworkin e Robert Alexy, é certo que suas análises fecundaram uma nova dogmática jurídica. O protagonismo dos princípios dentro do ordenamento jurídico não se caracterizou como um mero apego metodológico a novas ideias abstratas. Foi muito mais do que isso. Provocou a mudança quanto ao modo de pensar o direito, que passou a reconhecer que os valores expressos pelos princípios integram e permeiam todo o sistema jurídico ainda que não positivados em um texto normativo ${ }^{50}$.

As Constituições que se seguiram no segundo pós-guerra passaram a prever mais princípios do que regras. No entanto, a Constituição Brasileira de 1988, embora se enquadre na lista daquelas que foram editadas após a Segunda Guerra Mundial, não seguiu aquela lógica.

Conforme apontou Humberto Ávila, a nossa Constituição tem ambas as espécies normativas (princípios e regras), mas muito mais regras do que princípios. Cada qual com função diferente, não se pode falar da primazia de um sobre o outro, mas tão só de "funções e eficácias diferentes e complementares". Isso porque,

conflitos normativos que envolvem valores ou opções políticas em tensão insuperáveis pelas formas hermenêuticas tradicionais" (Barcellos, Ana Paula de. Ponderação, racionalidade e atividade jurisdicional. In: Barroso, Luís Roberto (org.). A reconstrução democrática do direito público no Brasil - Rio de Janeiro: Renovar, 2007, p. 262.

${ }^{49}$ Alexy, Robert. Teoria dos direitos fundamentais. - São Paulo: Malheiros Editores, 2006, p. 102.

${ }^{50}$ Barroso, Luís Roberto. Interpretação e aplicação da constituição: fundamentos de uma dogmática constitucional transformadora. $6^{\mathrm{a}}$ ed. rev., atual. e ampl. São Paulo: Saraiva, 2004, p. 338. conforme demonstra dito autor, dentro da nossa realidade constitucional o legislador constituinte originário decidiu, "na maior parte dos casos, fazer uma ponderação pré-legislativa”. Ou seja, as regras foram incluídas na Constituição para resolver um conflito, conhecido ou antecipável, e funcionando como um bloqueio para ao uso das razões decorrentes dos princípios. Por isso, como diz, "a existência de uma regra constitucional elimina a ponderação horizontal entre princípios pela existência de uma solução legislativa prévia destinada a eliminar ou diminuir os conflitos de coordenação, conhecimento, custos e controle do poder" ${ }^{21}$.

\subsection{O modelo de princípios possibilita um défit de racionalidade e permite uma abertura para o decisionismo?}

Paralelo ao desenvolvimento dogmático quanto a distinção entre regras e princípios, as Constituições do segundo pós-guerra reclamou aos seus intérpretes a tarefa de aplicar aqueles novos valores através de uma tomada de posição moral na busca de sua efetividade ${ }^{52}$.

A insuficiência do modelo positivista e a necessidade de eficácia das normas de direito fundamental provocou o reconhecimento da força normativa das Constituições, que deixaram de ser consideradas como mera folha de papel ${ }^{53}$. Os princípios nela constantes passaram a irradiar para todo o ordenamento jurídico e a assumir o status de norma jurídica ${ }^{54}$. Assim, o pluralismo que

${ }^{51}$ No mesmo sentido: "num conflito, efetivo ou aparente, entre uma regra constitucional e um princípio constitucional, deve vencer a regra" (Avila, Humberto. Neoconstitucionalismo: entre a ciência do direito e o direito da ciência. In: Sarmento, Daniel (Coord.) Filosofia e teoria constitucional contemporânea. Rio de Janeiro: Editora Lumen Juris, 2009, p. 190-191).

${ }^{52}$ Pozzolo, Susanna. Un constitucionalismo ambiguo. In: Carbonell, Miguel. Neoconstitucionalismo(s). Madrid: Editorial Trotta, 2003, 190.

${ }^{53}$ Lassale, Ferdinand. A essência da constituição. Trad. Walter Stonnes. Rio de Janeiro: Líber Juris, 1985.

${ }^{54}$ Vide comentários ao item anterior. 
antes era protegido apenas de modo formal, dentro da Constituição, se projeta para fora, para as leis ${ }^{55}$.

Desse modo, o Poder Judiciário fica no centro do holofote da cena política. Como disse Daniel Sarmento ${ }^{56}$, a leitura clássica do princípio da separação de poderes cede espaço para outras visões, onde o ativismo judicial é exercido na defesa dos valores constitucionais.

Não obstante isso, o mesmo autor vê "com reticências a sedimentação, na nossa cultura jurídica, da visão de que o grande - se não o único - intérprete da Constituição seria o Poder Judiciário". Alerta que o neoconstitucionalismo brasileiro tem pecado pelo excesso com essas ideias, cujo efeito colateral pode ser muito perigoso, pois a "ditadura de toga pode não ser muito melhor do que a ditadura de farda ..."57.

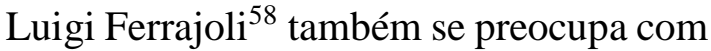
esses riscos. As leis, segundo ele, estão cada vez mais redigidas em linguagem obscura, tortuosa e em grande número, o que dá lugar a "intrincados enredos e labirintos legislativos", ao ponto de levar o Tribunal Constitucional italiano a arquivar o clássico principio penal da não exclusão de culpabilidade pela ignorância. Alerta que a racionalidade da lei, a qual Hobbes contrapôs a "iuris prudência" ou "sabedoria dos juízes" do velho direito comum, está sendo dissolvida por um legislador ainda mais desordenado, o que abre caminho para a discricionariedade dos juízes e a

\footnotetext{
${ }^{55}$ Maliska, Marcos Augusto. Pluralismo jurídico e direito moderno: notas para pensar a racionalidade jurídica na modernidade. Juruá, 2000.

56 Sarmento, Daniel. O neoconstitucionalismo no brasil: riscos e possibilidades. In: Sarmento, Daniel (Coord.) Filosofia e teoria constitucional contemporânea. Rio de Janeiro: Editora Lumen Juris, 2009, p. 119.

${ }^{57}$ Sarmento, Daniel. O neoconstitucionalismo no brasil: riscos e possibilidades. In: Sarmento, Daniel (Coord.) Filosofia e teoria constitucional contemporânea. Rio de Janeiro: Editora Lumen Juris, 2009, p. 139.

${ }^{58}$ Ferrajoli, Luigi. Pasado y futuro des estado de derecho. In: Carbonell, Miguel. Neoconstitucionalismo(s). Madri: Editorial Trotta, 2003.

59 Pereira, Ana L. P.. Jurisdição Constitucional na constituição federal de 88: entre ativismo e auto-contenção.
}

formação jurisprudencial, administrativa ou privada do direito, conforme o antigo modelo premoderno, causando perda da certeza, eficiência e garantias.

Dentro dessa mesma linha de ideias, Ana Lucia Pretto Pereira ${ }^{59}$ alerta quanto a necessidade de ampliação do debate jurídico acerca do ativismo e da auto-contenção judicial. É que, conforme destacado pela autora, a abertura das "portas ao magistrado para que interprete a Constituição da maneira que julgar mais adequada ao caso em exame" pode "encobrir um decisionismo crônico da jurisdição constitucional".

Diante de todos os riscos que o ativismo judicial pode causar, Ronald Dworkin idealiza a visão do Direito como um romance em cadeia que busca ilustrar um novo modo hermenêutico voltado para garantir o maior grau possível de coerência no Direito e nas decisões judiciais, evitando-se a insegurança jurídica gerada quando o decisionismo se instala ${ }^{60}$.

O resultado disso tudo é que o juiz, ao interpretar as normas jurídicas incidentes no caso concreto realiza uma atividade criativa do direito, que servirá para casos futuros semelhantes ${ }^{61}$.

Em uma direção diferente, mas com o mesmo propósito de romper os padrões positivistas tradicionais que deram margem às atrocidades ocorridas na Segunda Guerra Mundial, Friedrich Muller ${ }^{62}$, autor pós-

In: Revista Eletrônica Direitos Fundamentais e Democracia. Disponível em: http://revistaeletronicardfd.unibrasil.com.br.

${ }^{60}$ Dworkin. Ronald. O império do direito. Trad. Jefferson Luiz Camargo. São Paulo: Martins Fontes, 1999.

${ }^{61}$ Reconhece-se a crítica que certa parte da doutrina formula contra a visão "contrafáticas dos intérpretes". Por todos: Sarmento, Daniel. Interpretação constitucional, précompreensão e capacidades institucionais do intérprete. In: Neto, Claudio Pereira; Sarmento, Daniel; Binenbojm, Gustavo. (Coords.). Vinte anos da constituição federal de 1988. Rio de Janeiro: Editora Lumen Juris, 2009.

${ }^{62}$ Muller, Friedrich. Tesis acerca de la estrutura de las normas jurídicas. Madrid: CEPC, 1989. 
positivista, desenvolveu a sua teoria estruturante das normas jurídicas, na qual discorre contra teoria dos princípios por compreender que o texto constitucional fornece tão somente o texto da norma, ou seja é uma forma prévia da norma jurídica. Esta, para ser alcançada, necessita passar por um processo de concretização, aferível de acordo com cada caso concreto, e onde são utilizados todos os recursos hermenêuticos disponíveis ${ }^{63}$.

Ocorre que essa nova forma de interpretar o Direito na busca da efetividade dos direitos fundamentais fez surgir argumentos que acusam o Poder Judiciário de carecer de legitimidade democrática para tratar de questões afetas à vontade da maioria. Alega-se que há um risco decorrente da subjetividade das decisões judiciais, pois a abertura do texto constitucional permitiria que o magistrado interpretasse a Constituição do modo que melhor julgasse adequado ao caso concreto, "podendo, muitas vezes, a aparente legitimidade da decisão encobrir um decisionismo crônico da jurisdição constitucional" 64 .

Mas isso não é assim. A atuação do judiciário não é ilimitada ou despida de qualquer freio. O seu novo papel, fundado na necessidade de atribuir efetividade aos direitos fundamentais, vem acompanhado do dever de racionalidade, ou seja justificação da tomada de decisão ${ }^{65}$.

\footnotetext{
${ }^{63} \mathrm{Na}$ mesma linha de princípios é a doutrina de Canotilho, que resume: “o texto da norma é o 'sinal linguístico'; a norma é o que se 'revela', 'designa' " (Canotilho, J.J.. Direito Constitucional. $5^{\mathrm{a}}$ ed. - Coimbra: Almedina, 1991, p. 225)

64 Pereira, Ana L. P.. Jurisdição Constitucional na constituição federal de 88: entre ativismo e auto-contenção. In: Revista Eletrônica Direitos Fundamentais e Democracia, p. $16 . \quad$ Disponível em: http://revistaeletronicardfd.unibrasil.com.br.

${ }^{65}$ Nesse sentido é a doutrina de Dworkin e Alexy.

66 Sarmento, Daniel. Interpretação constitucional, précompreensão e capacidades institucionais do intérprete. In: Neto, Claudio Pereira; Sarmento, Daniel; Binenbojm, Gustavo. (Coords.). Vinte anos da constituição federal de
}

Como bem sintetizou Daniel Sarmeto, em citação à Ronald Dworkin e John Rawls ${ }^{66}$ :

[...] cabe ao intérprete "filtrar a moral positiva
através do exercício da razão pública, buscando
fundamentar suas decisões em argumentos cuja
aceitabilidade pelos interlocutores não dependa da
adesão a qualquer credo religioso ou metafísico, ou
a qualquer compreensão particular sobre a 'vida boa'
- ainda quando se trate da compreensão
majoritariamente acolhida.

As doutrinas e Ronald Dworkin e Robert Alexy demonstram isso. Ambos autores, como visto linhas acima, desenvolveram o pensamento dominante nos dias de hoje no sentido de que os princípios ocupam o centro gravitacional do ordenamento jurídico e demandam uma atuação construtiva do seu intérprete de modo a não afastá-lo da coerência que se espera e que é exigida do ordenamento jurídico como um todo.

\section{CONCLUSÃO}

Em face do que foi desenvolvimento no presente artigo, pode-se dizer que o caminho seguido pelo Direito Constitucional no segundo pós-guerra, largamente conhecido como neoconstitucionalismo, não passou um cheque em branco ao julgador. Muito embora este novo momento do Direito tenha conferido maior abertura para o intérprete, é certo que o mesmo não legitima qualquer tipo de ditadura, ainda que de toga.

1988. Rio de Janeiro: Editora Lumen Juris, 2009, p. 316317. No mesmo sentido quanto ao uso da razão pública são os dizeres de Barroso, Luís Roberto. Curso de direito constitucional contemporâneo: os conceitos fundamentais e a construção do novo modelo - São Paulo: Saraiva, 2009, p. 71: "O uso da razão pública impota em afastar dogmas religiosos ou ideológicos - cuja validade é aceita apenas pelo grupo dos seus seguidores - e utilizar argumentos que sejam reconhecidos como legítimos por todos os grupos sociais dispostos a um debate franco, ainda que não concordem quanto ao resultado obtido em concreto. A razão pública consiste na busca de elementos constitucionais essenciais e em princípios consensuais de justiça, dentro de um ambiente de pluralismo político". 
Assim, não há um défit de racionalidade do Direito, mas a reestruturação do mecanismo para a tomada de decisão pelo intérprete. O princípio da proporcionalidade assume o papel fundamental nesse processo, pois serve como parâmetro para a verificação da legitimidade da decisão do legislador frente aos ditames constitucionais.

\section{REFERÊNCIAS}

Ávila, Humberto. Segurança jurídica: entre permanência, mudança e realização no direito tributário. São Paulo: Malheiros. 2011.

. Teoria dos princípios: da definição à aplicação de princípios jurídicos. São Paulo: Malheiros. 2008.

Barcellos, Ana Paula de. Ponderação, racionalidade e atividade jurisdicional. In: Barroso, Luís Roberto (org.). A reconstrução democrática do direito público no Brasil - Rio de Janeiro: Renovar, 2007.

Barroso, Luís Roberto. A reconstrução democrática do direito público no brasil. - Rio de Janeiro: Renovar, 2007.

Interpretação e aplicação da constituição: fundamentos de uma dogmática constitucional transformadora. $6^{a}$ ed. rev., atual. e ampl. São Paulo: Saraiva, 2004.

Curso de direito constitucional contemporâneo: os conceitos fundamentais e a construção do novo modelo - São Paulo: Saraiva, 2009.

Neoconstitucionalismo e constitucionalização do direito. Disponível em: <http://www.luisrobertobarroso.com.br/wpcontent/themes/LRB/pdf/neoconstitucionalismo_e_constitucionalizacao_do_direito_pt.pdf $>$. Acesso em: 04 out. 2015.

Os princípios da razoabilidade e da proporcionalidade. Artigo publicado na Disponível em: <http://www.acta-diurna.com.br/biblioteca/doutrina/d19990628007.htm>. Acesso em: 04 out. 2015.

Bobbio, Norberto. Teoria do ordenamento jurídico. - Brasília: Editora Universidade de Brasília, 10ª ed., 1999.

Brasil. Constituição da República Federativa do Brasil.

Camargo, Margarida L.. A nova hermenêutica. in: Sarmento, Daniel (Coord.) Filosofia e teoria constitucional contemporânea. Rio de Janeiro: Editora Lumen Juris, 2009.

Canotilho, J.J., Gomes. Direito Constitucional. $6^{\mathrm{a}}$ ed. Coimbra: Livraria Almedina. . ; Mendes, Gilmar F.; Sarlet, Ingo W.; Streck, Lenio L. (Coords.). Comentários à constituição do brasil. São Paulo: Saraiva/Almedina, 2013. 
Casamiglia, Albert. El concepto de integridade em Dworkin. In: Doxa. Biblioteca Virtual Miguel de Cervantes. Diponível em: http://www.cervantesvirtual.com/obra/el-concepto-deintegridad-en-dworkin-0/. Acesso em: 22 de setembro de 2015.

Da Silva, Virgílio Afonso. Interpretação Constitucional e sincretismo metodológico. In: Da Silva, Virgílio Afonso (org.). Interpretação constitucional 1 ${ }^{\mathrm{a}}$ ed. - São Paulo: Melheiros, 2005.

Direitos fundamentais: conteúdo essencial, restrições e eficácia. 2009.

Dworkin, Ronald. Levando os direitos a sério. - São Paulo: Martins Fontes, 2002.

Fontes, 1999.

O império do direito. Trad. Jefferson Luiz Camargo. São Paulo: Martins

Ferrajoli, Luigi. Pasado y futuro des estado de derecho. In: Carbonell, Miguel. Neoconstitucionalismo(s). Madri: Editorial Trotta, 2003.

Kelsen. Hans. Teoria pura do direito. $4^{\mathrm{a}}$ ed. Coimbra, 1976.

Maliska, Marcos Augusto. Pluralismo jurídico e direito moderno: notas para pensar a racionalidade jurídica na modernidade. Juruá, 2000.

Maluf, Sahid. Teoria geral do Estado. 23ª ed. rev. e atual. São Paulo: Saraiva: 1995

Martins, Fernando Barbalho. Do direito à democracia: neoconstitucionalismo, princípio democrático e a crise no sistema representativo. Rio de Janeiro: Lumen Iuris, 2007.

Miranda, Jorge. Teoria do Estado e da Constituição. Coimbra: Coimbra Editora, 2002

Montesquieu. Do espírito das leis. São Paulo: Martin Claret, 2010.

Moraes, Alexandre de. Direito constitucional. - 28 a ed. - São Paulo: Atlas, 2012

Muller, Friedrich. Tesis acerca de la estrutura de las normas jurídicas. Madrid: CEPC, 1989

Neto, Cláudio Pereira de Souza. Teoria constitucional e democracia deliberativa: um estudo sobre o papel do direito na garantia das condições para a cooperação na deliberação democrática. - Rio de Janeiro: Renovar, 2006.

Novais, Jorge Reis. Direitos fundamentais e justiça constitucional. Coimbra: Coimbra, 2012

Pereira, Ana L. P.. Jurisdição Constitucional na constituição federal de 88: entre ativismo e auto-contenção. In: Revista Eletrônica Direitos Fundamentais e Democracia. Disponível em: http://revistaeletronicardfd.unibrasil.com.br.

O conteúdo e alcance do art. $5^{\circ}, \S 1^{\circ}$, da CF/1988. In: Cléve. Clémerson M..

Direito constitucional brasileiro. V. 1 - Teoria da Constituição e Direitos Fundamentais. São Paulo: Revista dos Tribunais, 2014. 
Pereira, Jane Reis Gonçalves. Interpretaçao constitucional e direitos fundamentais: uma contribuição ao estudo das restrições aos direitos fundamentais na persectiva da teoria dos princípios. - Rio de Janeiro: Renovar, 2006.

Pozzolo, Susanna. Un constitucionalismo ambiguo. In: Carbonell, Miguel. Neoconstitucionalismo(s). Madrid: Editorial Trotta, 2003.

Reale, Miguel. Lições preliminares de direito - 24ª ed. - São Paulo: Saraiva, 1998.

Robert, Alexy. Teoria dos direitos fundamentais. - São Paulo: Malheiros Editores, 2008. . Teoria dos Princípios. São Paulo: Malheiros, 2008.

Rousseau, J. J.. Do contrato social. Disponível em: <http://www.dominiopublico.gov.br/download/texto/cv00014a.pdf >. Acesso em: 04 out. 2015.

Sanchis, Luís Prieto. Neoconstitucionalismo y ponderación judicial. In: Carbonell, Miguel. Neoconstitucionalismo(s). Madrid: Editorial Trotta, 2003.

Justicia constitucional y derechos fundamentales. Madrid: Trotta, 2003.

Sarmento, Daniel. Interpretação constitucional, pré-compreensão e capacidades institucionais do intérprete. In: Neto, Claudio Pereira; Sarmento, Daniel; Binenbojm, Gustavo. (Coords.). Vinte anos da constituição federal de 1988. Rio de Janeiro: Editora Lumen Juris, 2009.

O neoconstitucionalismo no brasil: riscos e possibilidades. In: Sarmento, Daniel (Coord.) Filosofia e teoria constitucional contemporânea. Rio de Janeiro: Editora Lumen Juris, 2009.

Estado 2, 2006

Umbiquidade constitucional: os dois lados da moeda. Revista de Direito do

Schier, Paulo Ricardo. A constitucionalização do direito no contexto da constituição de 1988. In: Clève, Clémerson Merlin (org). Direito constitucional brasileiro - teoria da constituição e direitos fundamentais. São Paulo: Revista dos Tribunais, Volume 1, 2014.

Streck, Lenio Luiz. Jurisdição constitucional e decisão jurídica - $4^{\mathrm{a}}$ ed. - São Paulo: Editora Revista dos Tribunais, 2014.

Vasconcellos, Fernando Andreoni. Hermeneutica jurídica e derrotabilidade. Curitiba: Juruá, 2010.

Zagrebelsky, Gustavo. El derecho dúctil: ley, derechos, justicia. 6. ed. Madrid: Trotta, 2007;

Zolo, Danilo. Teoria e crítica do estado de direito. In: Costa, Pietro; Zolo, Danilo (orgs.) O estado de direito - historia, teoria e crítica. São Paulo: Martins Fontes, 2006. 
Recebido em: 15/12/2016 Aceito em: 19/02/2017 
